\title{
Predictors of severe asthma attack re-attendance in Ecuadorian children: a cohort study
}

\author{
Cristina Ardura-Garcia ${ }^{1,2}$, Erick Arias ${ }^{3}$, Paola Hurtado ${ }^{3}$, Laura J. Bonnett $\mathbb{1}^{4}$, \\ Carlos Sandoval ${ }^{3}$, Augusto Maldonado ${ }^{5}$, Lisa J. Workman ${ }^{6}$, \\ Thomas A.E. Platts-Mills ${ }^{6}$, Philip J. Cooper ${ }^{3,7,8,11}$ and John D. Blakey ${ }^{9,10,11}$
}

Affiliations: ${ }^{1}$ Institute of Social and Preventive Medicine, University of Bern, Bern, Switzerland. ${ }^{2}$ Liverpool School of Tropical Medicine, Liverpool, UK. ${ }^{3}$ Fundación Ecuatoriana Para Investigación en Salud, Quito, Ecuador. ${ }^{4}$ Dept of Biostatistics, University of Liverpool, Liverpool, UK. ${ }^{5}$ Colegio de Ciencias de la Salud, Universidad San Francsico de Quito, Quito, Ecuador. ${ }^{6}$ Asthma and Allergic Diseases Center, University of Virginia, Charlottesville, VA, USA. ${ }^{7}$ Facultad de Ciencias Medicas, de la Salud y la Vida, Universidad Internacional del Ecuador, Quito, Ecuador. ${ }^{8}$ Institute of Infection and Immunity, St George's University of London, London, UK. ${ }^{9}$ Respiratory Medicine, Sir Charles Gairdner Hospital, Perth, Australia. ${ }^{10}$ Medical School, Curtin University, Perth, Australia. ${ }^{11}$ Both authors contributed equally.

Correspondence: Cristina Ardura-Garcia, Institute of Social and Preventive Medicine, University of Bern, Mittelstrasse 43, 3012 Bern, Switzerland. E-mail: crisarduradgmail.com

@ERSpublications

Among children in a low-resource setting in Latin America, younger age, an established asthma diagnosis and history of severe asthma attacks in the previous year were associated with recurrence of severe asthma attacks, irrespective of biomarkers http://bit.ly/2TBzJcP

Cite this article as: Ardura-Garcia C, Arias E, Hurtado P, et al. Predictors of severe asthma attack re-attendance in Ecuadorian children: a cohort study. Eur Respir J 2019; 54: 1802419 [https://doi.org/ 10.1183/13993003.02419-2018].

ABSTRACT Asthma is a common cause of emergency care attendance in low- and middle-income countries (LMICs). While few prospective studies of predictors for emergency care attendance have been undertaken in high-income countries, none have been performed in a LMIC.

We followed a cohort of 5-15-year-old children treated for asthma attacks in emergency rooms of public health facilities in Esmeraldas City, Ecuador. We collected blood and nasal wash samples, and performed spirometry and exhaled nitric oxide fraction measurements. We explored potential predictors for recurrence of severe asthma attacks requiring emergency care over 6 months' follow-up.

We recruited 283 children of whom 264 (93\%) were followed-up for $\geqslant 6$ months or until their next asthma attack. Almost half (46\%) had a subsequent severe asthma attack requiring emergency care. Predictors of recurrence in adjusted analyses were (adjusted OR, 95\% CI) younger age $(0.87,0.79-0.96$ per year), previous asthma diagnosis $(2.2,1.2-3.9)$, number of parenteral corticosteroid courses in previous year $(1.3,1.1-1.5)$, food triggers $(2.0,1.1-3.6)$ and eczema diagnosis $(4.2,1.02-17.6)$. A parsimonious Cox regression model included the first three predictors plus urban residence as a protective factor (adjusted hazard ratio $0.69,95 \%$ CI $0.50-0.95$ ). Laboratory and lung function tests did not predict recurrence.

Factors independently associated with recurrent emergency attendance for asthma attacks were identified in a low-resource LMIC setting. This study suggests that a simple risk-assessment tool could potentially be created for emergency rooms in similar settings to identify higher-risk children on whom limited resources might be better focused.

This article has supplementary material available from erj.ersjournals.com

Received: 20 Dec 2018 | Accepted after revision: 11 Aug 2019

Copyright $\odot$ ERS 2019. This article is open access and distributed under the terms of the Creative Commons Attribution Licence 4.0. 


\section{Introduction}

Severe asthma attacks requiring emergency care, hospital admission or systemic corticosteroids [1] are a common source of preventable morbidity in children. Asthma attacks are associated with impaired lung function [2], anxiety in patients and families [3] and elevated healthcare and family costs [4]. Many asthma attacks are preventable, either by avoiding triggers or by appropriate preventive treatment. Inhaled corticosteroids (ICS) reduce the probability of asthma attacks by $\sim 40 \%$ [5] and can attenuate the decline in lung function associated with asthma attacks [2]. Because ICS have associated side-effects [6-8] and costs, use should be targeted at those at greater risk of attacks or persistent symptoms, especially when resources are limited. Identifying children with a greater risk of asthma attacks is crucial for optimisation of asthma treatment, particularly in low-resource settings where under-diagnosis and lack of capacity for long-term management are major problems.

In most Latin American countries where health resources and specialist follow-up care are limited $[9,10]$, children with asthma are mainly seen in emergency rooms (ER) during acute attacks [11, 12]. The ER represents an opportunity to identify children at higher risk of future attacks. Factors that have been associated previously with recurrent asthma attacks requiring emergency care in paediatric cohort studies include history of previous ER attendance for attacks, younger age, black ethnicity and low socioeconomic status [13-16]. However, these studies were undertaken almost exclusively in North America and did not evaluate potential usefulness of biomarkers commonly available in higher-income settings [16]. No prospective studies investigating ER re-attendance for asthma from lower-income settings were identified in a recent systematic review [16].

We undertook a prospective cohort study to identify clinical factors and biomarkers associated with recurrent severe asthma attacks in children presenting with an asthma attack at regional ERs in a limited-resource setting in Latin America.

\section{Methods}

Study population and design

This prospective cohort study was done in the city of Esmeraldas, Ecuador (population 150000, of mainly Afro-Ecuadorian ethnicity) in the north-western coastal province of Esmeraldas. Patients were recruited from the city's public hospital, Delfina Torres de Concha Hospital, which offers free attention and treatment; the Instituto Ecuatoriano de Seguro Social Esmeraldas hospital, which offers free treatment to those paying national insurance; and the three largest public health centres in the city with 24-h emergency care.

Children aged 5-15 years treated at emergency departments for asthma attacks (defined as bronchodilator-responsive wheeze) were recruited between May 2014 and September 2015. Children with other chronic conditions were excluded. Written consent was obtained from the child's caregiver and minor assent from children aged $>7$ years. A total of 283 children were recruited. The protocol was approved by the bioethics committees of the Liverpool School of Tropical Medicine (Liverpool, UK) and the Universidad San Francisco de Quito (Quito, Ecuador).

\section{Measurements of exposures and outcomes}

Data were collected in Spanish from the child's caregiver using a modified version of the International Study of Asthma and Allergies in Childhood (ISAAC) phase II questionnaire [17], which has been extensively field-tested [18, 19], together with additional questions regarding potential risk factors for recurring asthma attacks. A detailed description of variables studied is included in supplementary table S1. The Childhood Asthma Control Test (C-ACT) [20] was completed by the child and guardian for children aged $<12$ years or the ACT [21] for those aged $\geqslant 12$ years. Weight and height were measured. A blood sample was drawn for haematocrit, blood count and plasma assays. Total and specific (s)IgE for Dermatophagoides pteronyssinus and Blomia tropicalis were measured using the CAP system (Pharmacia Diagnostics, Uppsala, Sweden) in 86 random plasma samples, of which 60 were tested for German cockroach and food mix (egg white, milk, cod, wheat, peanut, soy)-specific IgE. A positive assay for sIgE was defined as $>0.70 \mathrm{kU} \cdot \mathrm{L}^{-1}$. A nasal wash with saline was performed to determine the relative proportion of granulocytes (eosinophils versus neutrophils) using a protocol modified from a previous study [22] (see the supplementary material for detailed technique). Participants returned 2 weeks after recruitment (or up to 3 weeks if during the 2-week appointment they were still taking daily salbutamol or oral corticosteroids or had wheezing) for pre- and post-bronchodilator spirometry (MicroLoop spirometer, Micro Direct, Lewiston, ME, USA) and exhaled nitric oxide fraction $\left(F_{\text {eNO }}\right)$ (NObreath; Bedfont Scientific, Maidstone, UK). At this time, the Paediatric Asthma Quality of Life Questionnaire (PAQLQ) [23] and Newcastle Asthma Knowledge Questionnaire (NAKQ) [24, 25] were completed. Asthma severity was classified using the Ecuadorian Asthma Consensus 2011 [26], which closely follows the Global Initiative for Asthma 
(GINA) 2008 [27] and Spanish 2009 asthma guidelines [28]. Participants were offered inhaled $\beta_{2}$-agonists as relievers with or without corticosteroids for long-term treatment in accordance with these guidelines. In addition, they were provided with a standardised short education on asthma, recommendations for future asthma attacks and written asthma action plans.

Each participant was followed-up with twice-monthly telephone calls asking about asthma attacks (number, severity, duration and treatment received) and told to contact the study team immediately following an attack. A severe asthma attack was defined as an acute exacerbation of respiratory symptoms (difficulty breathing and wheezing that improved with bronchodilators) requiring either 1) urgent care at an ER or 2) unscheduled medical visit with prescription of systemic corticosteroids (for $\geqslant 3$ days if oral) [1]. Hospital and health centre records were checked twice weekly to record unscheduled visits for attacks.

\section{Statistical analysis}

The primary outcome was recurrence of an asthma attack requiring emergency care and occurring between 2 weeks and 6 months after the index attack. Only the first recurrence was considered in the analysis among those with more than one attack during follow-up. Only variables measured at baseline were studied as risk factors. Continuous variables were compared using t-tests or Mann-Whitney U-tests, as appropriate. Categorical variables were compared using Fisher's exact test. Multivariable logistic regression was used to evaluate the effects of multiple risk factors for emergency care re-attendance on risk of recurrence of asthma attacks. Only children followed-up until their first asthma attack recurrence or for a minimum of 6 months exacerbation-free were included in this analysis. A time-to-event analysis was performed using a multivariable Cox proportional hazard model, including all children who completed $\geqslant 2$ weeks of follow-up. Collett's method of variable selection [29] was used with a p-value threshold of 0.2, and confounding and interactions between variables were assessed. The parsimonious logistic and Cox models were selected based on explained variation $\left(\mathrm{R}^{2}\right)$. The proportional hazards assumption required by the Cox model was tested via the inclusion of time-dependent variables. The assumption was valid for all included variables.

The predictive ability of the models was evaluated by estimating the area under the receiver operating characteristics curve (AUC) [30] and its 95\% confidence interval, with 0.5 indicating a model with no discriminating power and 1.0 a perfectly discriminating model [31]. Internal validity was then assessed by bootstrapping using 200 random bootstrap samples with replacement, to evaluate potential bias (over- or under-fitting). Optimism in regression coefficients due to overfitting was estimated by measuring the difference between the model's c-statistic (apparent c-statistic) and the c-statistic computed by nonparametric bootstrap resampling (internal bootstrap validation c-statistic) [32].

Statistical analyses were performed using Stata 13.1 with significance set at $p<0.05$. Details of sample size calculations and missing data strategy are provided in the supplementary material.

\section{Results}

Out of the 283 children recruited, 13 (4.6\%) were lost to follow-up after the initial visit, and 264 (93\%) were followed-up until their next asthma attack or a minimum of 6 months exacerbation-free. Of these, $121(46 \%)$ had at least one subsequent asthma attack requiring emergency care during the first 6 months of follow-up (figure 1). The median follow-up time was 408 days (interquartile range (IQR) 265-541 days, range 44-697 days) and the median time to a subsequent asthma exacerbation was 91 days (IQR 39178 days). Figure 2 shows time to first recurrence of a severe asthma attack.

Tables 1 and 2 show characteristics for the 264 children completing 6 months' follow-up or until first asthma attack recurrence, stratified by re-admission status at 6 months' follow-up. Available data for each variable are shown in supplementary table S1. Data for allergy and inflammatory markers and lung function are shown in figure 3. 39\% (107 out of 272) of all children had blood eosinophilia ( $>500$ cells $\mu \mathrm{L}^{-1}$ ) and $72 \%$ had nasal eosinophilia (>5\%) [33]. Median $F_{\mathrm{eNO}}$ for the whole sample was $33 \mathrm{ppb}$ (IQR 3-79 ppb). Median forced expiratory volume in $1 \mathrm{~s}\left(\mathrm{FEV}_{1}\right)$ in 223 children who underwent spirometry was $97 \%$ predicted (IQR $86-107 \%$ pred), of whom 30 (13\%) had values below the lower limit of normal. Median pre-bronchodilator $\mathrm{FEV}_{1} /$ forced vital capacity ratio was $91 \%$ (IQR $85-97 \%$ ), median $\mathrm{FEV}_{1}$ increase after inhaled bronchodilator was 6.4\% (IQR 2-14\%) and 109 (49\%) had a positive bronchodilator response (increase in $\mathrm{FEV}_{1}>12 \%$ ). IgE was measured in a random sample of 86 participants: total IgE (median $770 \mathrm{kU} \cdot \mathrm{L}^{-1}$, IQR $329-1376 \mathrm{kU} \cdot \mathrm{L}^{-1}$ ), and mite (D. pteronyssinus and $B$. tropicalis) IgE (81\% positive). Of the 60 samples tested for specific IgE for cockroach and food allergens, $82 \%$ were positive for any allergen.

In univariable analyses (tables 1 and 2), risk factors for recurrence were younger age, early-life severe respiratory illness, food triggers, previous asthma diagnosis, number and severity of asthma attacks over 


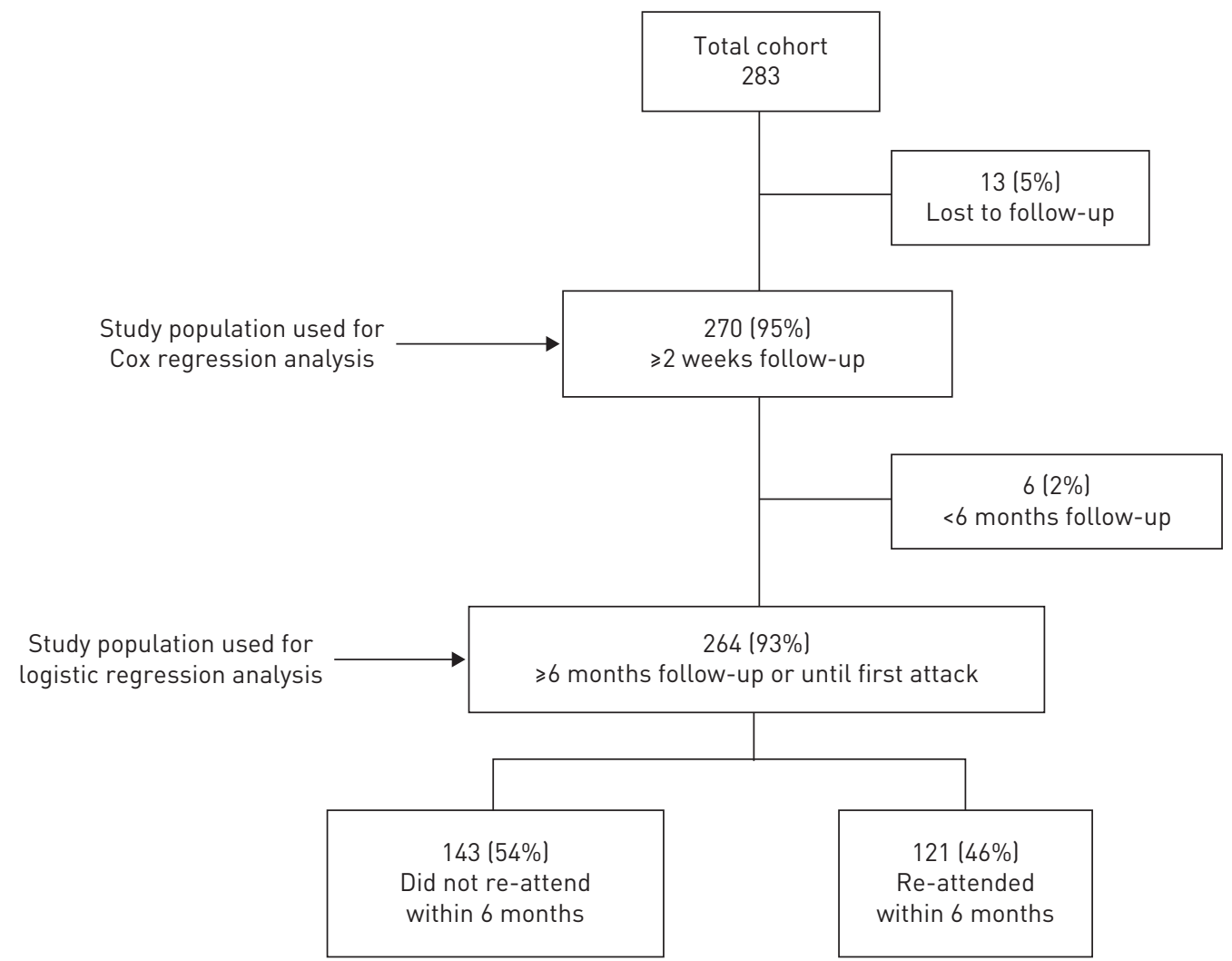

FIGURE 1 Recruitment and follow-up of participants.

the previous year and lower haemoglobin levels (mean \pm SD recurrence $12.9 \pm 0.87$ versus non-recurrence 13.1 $\pm 0.84, \mathrm{p}=0.032$ ). There were no differences in lung function or inflammation parameters (figure 3 ). Positivity for IgE specific to any allergen did not vary by recurrence status (recurrence 33 (79\%) out of 42 versus non-recurrence 37 (84\%) out of 44). The parents of children with recurrence had less specific asthma knowledge (NAKQ score) (OR 0.91 per 1 point, 95\% CI 0.85-0.98 per 1 point) and children had lower PAQLQ emotional domain scores (OR 0.72 per 1 point, 95\% CI 0.55-0.94 per 1 point) (supplementary table S2). No differences were seen between the two groups for asthma control (ACT and C-ACT scores) or PAQLQ total, symptoms or activity scores (supplementary table S2). Further results concerning food triggers for asthma attacks are included in the supplementary material.

The multivariable logistic regression model for risk of severe asthma attack recurrence showed independent risk factors to be younger age, a previous asthma diagnosis, food triggers, number of

FIGURE 2 Kaplan-Meier curve of time to first recurrence of severe asthma attacks. ER: emergency room.

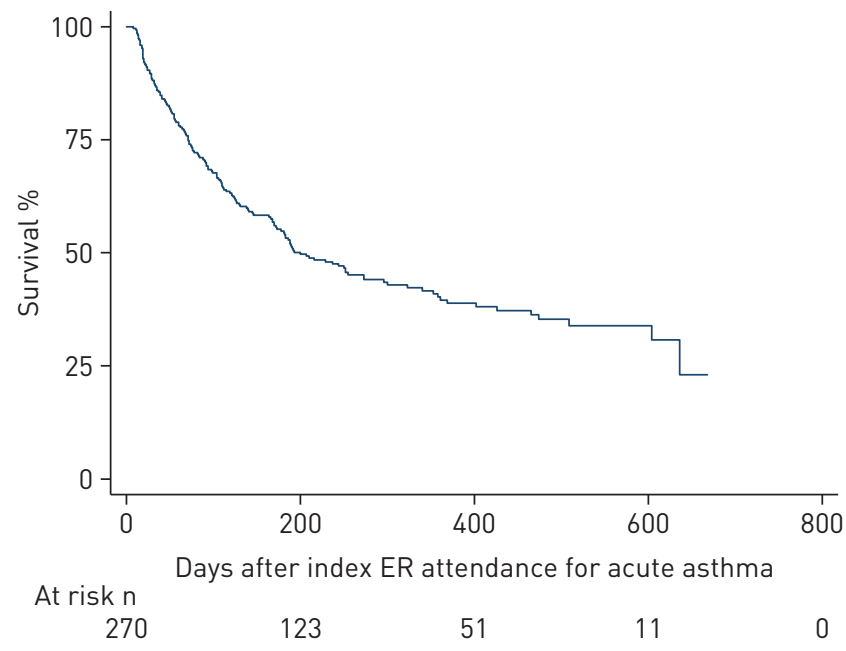


TABLE 1 Sociodemographic characteristics, personal and family history of 264 participants followed-up for 6 months or until first asthma attack recurrence, stratified by recurrence status at 6 months

\begin{tabular}{|c|c|c|c|c|}
\hline & \multirow[t]{2}{*}{ Total cohort } & \multicolumn{3}{|c|}{ Second asthma attack within 6 months } \\
\hline & & Yes & No & p-value \\
\hline $\begin{array}{l}\text { Subjects } \mathrm{n} \\
\text { Sociodemographic characteristics }\end{array}$ & 264 & 121 & 143 & \\
\hline Age years & $8(6-11)$ & $7(5-10)$ & $9(7-11)$ & $<0.001$ \\
\hline Male & 59 & 60 & 59 & 0.900 \\
\hline \multicolumn{5}{|l|}{ Ethnicity } \\
\hline Afro-Ecuadorian & 54 & 52 & 55 & 0.963 \\
\hline Mestizo & 43 & 45 & 42 & \\
\hline White & 2 & 2 & 1 & \\
\hline Other & 2 & 2 & 2 & \\
\hline $\mathrm{BMI} \mathrm{kg} \cdot \mathrm{m}^{-2}$ & $16.6(15.1-19.4)$ & $16.4(15.0-19.2)$ & $16.9(15.1-19.7)$ & 0.265 \\
\hline At least one sibling & 90 & 89 & 91 & 0.547 \\
\hline $\begin{array}{l}\text { Years of study by mother }+ \text { years of } \\
\text { study by father }\end{array}$ & $24(18-28)$ & $24(18-28)$ & $24(19-29)$ & 0.304 \\
\hline Pets at home & 43 & 45 & 42 & 0.708 \\
\hline Second-hand smoke exposure & 18 & 17 & 21 & 0.474 \\
\hline Humid household & 47 & 4 & 51 & 0.137 \\
\hline Urban setting & 66 & 60 & 70 & 0.094 \\
\hline Intense traffic near house & 30 & 30 & 30 & 1.000 \\
\hline Monthly household income USD & $400(255-700)$ & $400(260-700)$ & $350(250-700)$ & 0.981 \\
\hline \multicolumn{5}{|l|}{ Personal and family history } \\
\hline Early-life respiratory illness & 49 & 59 & 40 & 0.013 \\
\hline Allergic rhinitis ever & 72 & 74 & 70 & 0.490 \\
\hline Allergic rhinitis diagnosis & 21 & 20 & 21 & 0.878 \\
\hline Eczema ever & 13 & 14 & 12 & 0.713 \\
\hline Eczema diagnosis & 4 & 7 & 2 & 0.119 \\
\hline Paternal/maternal asthma & 46 & 53 & 41 & 0.175 \\
\hline $\begin{array}{l}\text { Paternal/maternal asthma/rhinitis/ } \\
\text { eczema }\end{array}$ & 68 & 70 & 66 & 0.788 \\
\hline
\end{tabular}

Data are presented as median (interquartile range) or \%, unless otherwise stated. Bold type represents statistically significant difference $(p<0.05)$. BMI: body mass index.

parenteral corticosteroid courses for acute asthma in the previous 12 months, and previous eczema diagnosis (table 3). The AUC of the model was 0.73 (95\% CI 0.67-0.79) (c-statistic) and the model explained $13 \%$ of variation. After internal validation (bootstrapping), AUC reduced to 0.72 and $\mathrm{R}^{2}$ to $14 \%$, indicating little overfitting of regression coefficients.

Table 4 shows the results of multivariable analysis for time to asthma attack recurrence. All children with $\geqslant 2$ weeks of follow-up were included in the analysis $(n=270)$. Children of younger age, with an existing asthma diagnosis, greater number of parenteral corticosteroid courses for acute asthma in the previous 12 months and not living in an urban setting showed a higher rate of recurrent asthma attacks requiring emergency care. The AUC of the model was 0.65 (95\% CI 0.60-0.70) (c-statistic) and overfitting of the model was estimated as $<1 \%$ after bootstrapping.

\section{Discussion}

We have identified independent predictors for emergency care re-attendance for severe asthma attacks among asthmatic children in a low-resource setting in a tropical region of coastal Ecuador, to our knowledge the first such prospective study set in low- and middle-income countries (LMICs) [16]. Having a previous severe asthma attack was the most reliable predictor of future risk: each acute parenteral corticosteroid course received during the previous year for acute asthma increased the odds of a subsequent severe attack by a factor of 1.28. Other factors associated with risk of attack or time to next attack were similar including younger age (both), an existing asthma (both) or eczema (risk of recurrence) diagnosis, food triggers (risk of recurrence) and rural residency (time to recurrence). We were unable to identify a biomarker that could usefully predict future risk of severe attacks. 
TABLE 2 Asthma characteristics ${ }^{\#}$ of 264 participants followed-up for 6 months or until first asthma attack recurrence, stratified by re-admission status at 6 months

\begin{tabular}{|c|c|c|c|c|}
\hline & \multirow[t]{2}{*}{$\begin{array}{l}\text { Total } \\
\text { cohort }\end{array}$} & \multicolumn{3}{|c|}{$\begin{array}{l}\text { Second asthma attack within } \\
\qquad 6 \text { months }\end{array}$} \\
\hline & & Yes & No & p-value \\
\hline Subjects $\mathrm{n}$ & 264 & 121 & 143 & \\
\hline Wheezing ever & 94 & 98 & 90 & 0.021 \\
\hline Wheezing past 12 months & 87 & 93 & 81 & 0.003 \\
\hline Attacks past 12 months & $3(2-6)$ & $5(2-6)$ & $3(1-5)$ & $<0.001$ \\
\hline Days since last attack & $60(30-120)$ & $60(30-120)$ & $60(30-150)$ & 0.120 \\
\hline \multicolumn{5}{|l|}{ Wheezing at night past 12 months } \\
\hline Never & 19 & 16 & 21 & 0.424 \\
\hline$<1$ night per week & 1 & 2 & 0.7 & \\
\hline$\geqslant 1$ night per week & 14 & 17 & 11 & \\
\hline Only during attacks & 66 & 66 & 67 & \\
\hline Severe attack past 12 months & 36 & 44 & 30 & 0.014 \\
\hline \multicolumn{5}{|l|}{ Wheezing with exercise } \\
\hline No & 36 & 30 & 41 & 0.188 \\
\hline Yes & 40 & 44 & 37 & \\
\hline Only during attacks & 24 & 27 & 23 & \\
\hline Previous asthma diagnosis & 64 & 77 & 54 & $<0.001$ \\
\hline Triggers & $4(2-6)$ & $4(3-6)$ & $4(2-5)$ & 0.117 \\
\hline Food as trigger & 37 & 46 & 29 & 0.006 \\
\hline \multicolumn{5}{|l|}{ Doctor visit for acute asthma past 12 months } \\
\hline None & 15 & 8 & 21 & $<0.001$ \\
\hline $1-3$ & 49 & 46 & 53 & \\
\hline $4-12$ & 27 & 32 & 23 & \\
\hline$>12$ & 8 & 14 & 3 & \\
\hline \multicolumn{5}{|l|}{ Doctor visit for asthma control past 12 months } \\
\hline None & 68 & 65 & 71 & 0.592 \\
\hline $1-3$ & 24 & 26 & 23 & \\
\hline $4-12$ & 7 & 8 & 7 & \\
\hline$>12$ & 0.4 & 0.8 & 0 & \\
\hline ICS treatment & 2 & 0.9 & 3 & 0.374 \\
\hline ER visit past 12 months for asthma & 76 & 79 & 74 & 0.388 \\
\hline ER asthma visits past 12 months & $2(1-4)$ & $3(1-6)$ & $2(0-3)$ & 0.006 \\
\hline $\begin{array}{l}\text { Courses of i.v./i.m. corticosteroids in past } 12 \text { months } \\
\text { for asthma }\end{array}$ & $0(0-1)$ & $1(0-3)$ & $0(0-1)$ & $<0.001$ \\
\hline Ever admitted for asthma & 25 & 34 & 18 & 0.004 \\
\hline Admitted for asthma in past 12 months & 8 & 12 & 4 & 0.034 \\
\hline Ever admitted to ICU for asthma & 10 & 13 & 7 & 0.102 \\
\hline
\end{tabular}

Data are presented as \% or median (interquartile range), unless otherwise stated. Bold type represents statistically significant difference $(p<0.05)$. ICS: inhaled corticosteroids; ER: emergency room; i.v./i.m.: intravenous/intramuscular; ICU: intensive care unit. " : all the variables were measured at baseline, at the moment of the index asthma attack.

\section{Comparison with previous studies and implications}

The observed recurrence rate of asthma attacks over 6 months (46\%) was higher than reported in similar studies from UK (37-38\%) [34], or US (12-17\%) [35], although consistent with our previous findings in this setting [11]. This and previous studies have identified a history of severe asthma attacks during the preceding year as a predictor for future asthma attacks [16]. Other predictors identified in univariate analysis were previous ER attendances, number of parenteral corticosteroid courses and unscheduled contacts for acute asthma. However, the number of parenteral corticosteroid courses was the only predictor among these associated with asthma attack recurrence in the multivariable model, probably because of the specific characteristics of our study setting (low rates of oral corticosteroid prescriptions and variable degree of severity of attacks).

Among sociodemographic characteristics, younger children had a greater risk of subsequent asthma attacks, as observed previously in studies undertaken in high-income countries [13, 14]. One possible explanation is that younger children suffer more from upper respiratory viral infections, such as rhinovirus, an important trigger for asthma attacks [36]. Children living in the city of Esmeraldas had a 


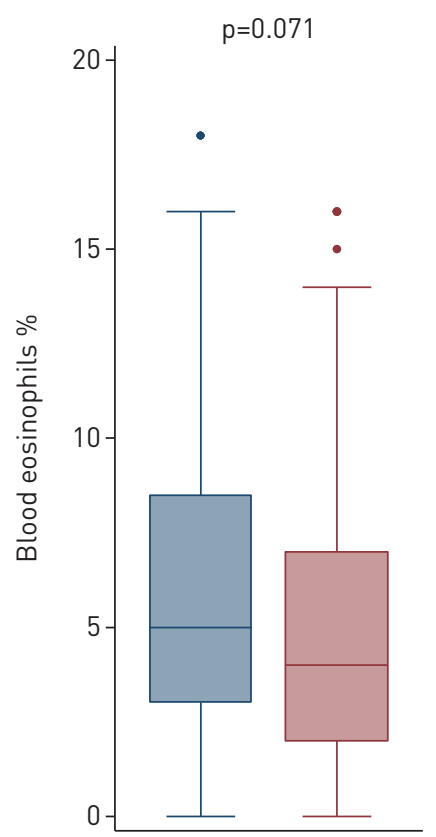

Blood eosinophils

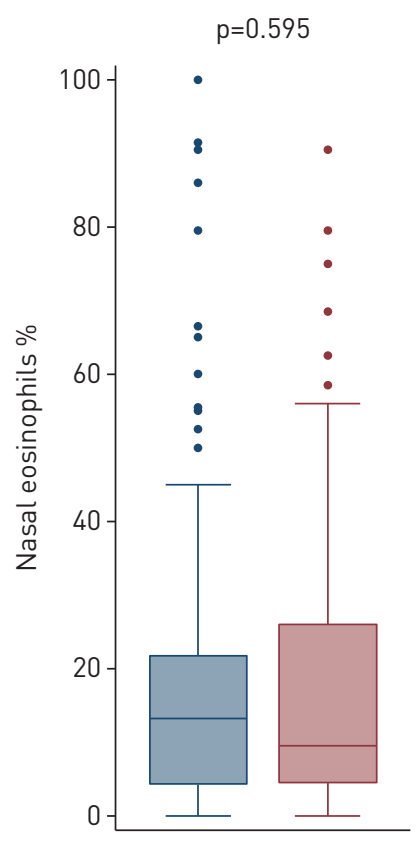

Nasal eosinophils
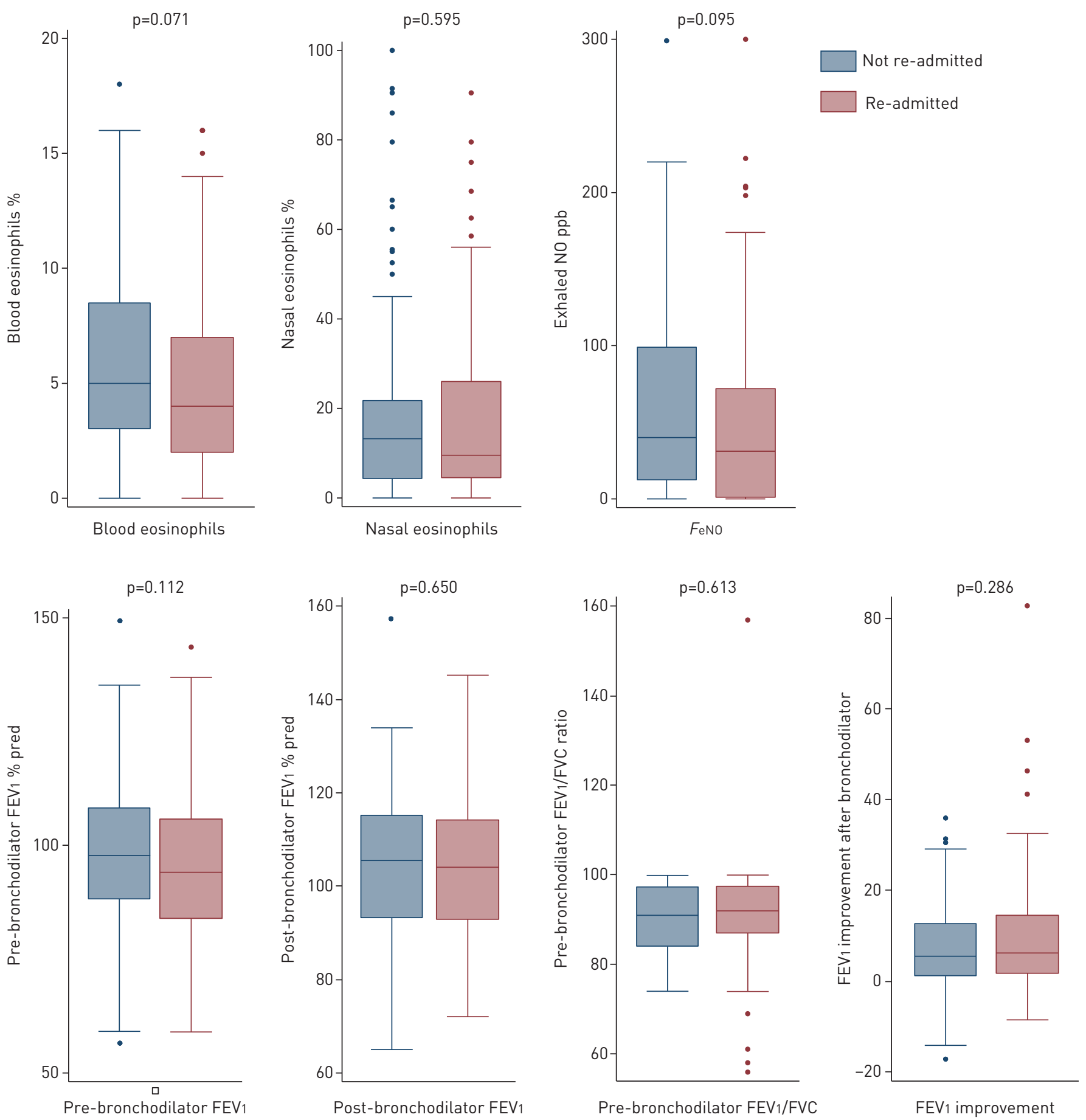

FIGURE 3 Allergy and inflammatory markers, and lung function of participants who had recurrent severe attacks (re-admitted) or not (not re-admitted) at 6 months follow-up. $n=264$. $p$-values represent intergroup differences using Mann-Whitney U-tests. NO: nitric oxide; $F_{\text {eNo: }}$ exhaled nitric oxide fraction; $\mathrm{FEV}_{1}$ : forced expiratory volume in $1 \mathrm{~s}$; FVC: forced vital capacity.

lower risk of subsequent asthma attacks compared to those from the surrounding rural area, a finding which has not been described previously. Distance to the emergency care facilities (located in the city) could have biased the results, with only children with more severe asthma travelling from rural areas to receive urgent medical attention. The association remained after controlling for variables such as educational level of parents and socioeconomic factors that have been associated with the risk of asthma attacks [14]. Two relevant characteristics that have been identified previously as risk factors for repeated asthma attacks did not predict future events in our study: low socioeconomic status and African ethnicity $[14,15]$. The population in which we worked in Esmeraldas was from poor neighbourhoods with a 
TABLE 3 Multivariable logistic regression for risk of emergency room re-attendance for severe asthma attacks during 6 months follow-up

\begin{tabular}{|c|c|c|c|c|}
\hline & $\begin{array}{l}\text { Crude OR } \\
(95 \% \mathrm{CI})\end{array}$ & p-value & $\begin{array}{l}\text { Adjusted OR \# } \\
(95 \% \mathrm{CI})\end{array}$ & p-value \\
\hline Age & $0.87(0.79-0.95)$ & 0.001 & $0.87(0.79-0.96)$ & 0.006 \\
\hline Previous asthma diagnosis & $2.78(1.62-4.76)$ & $<0.001$ & $2.17(1.19-3.94)$ & 0.011 \\
\hline $\begin{array}{l}\text { Number of } i . v . / i . m \text {. corticosteroid courses } \\
\text { during past } 12 \text { months }\end{array}$ & $1.36(1.15-1.61)$ & $<0.001$ & 1.28 (1.08-1.53) & 0.006 \\
\hline Food as trigger & $2.11(1.25-3.55)$ & 0.005 & $1.99(1.11-3.55)$ & 0.020 \\
\hline Eczema diagnosis & $3.26(0.84-12.6)$ & 0.086 & $4.22(1.02-17.54)$ & 0.048 \\
\hline
\end{tabular}

i.v.: intravenous; i.m.: intramuscular. $\mathrm{n}=264$. $^{\text {\# }}$ : adjusted odds ratios were adjusted for all other variables in the model.

probable high degree of African genetic admixture resulting in a relatively homogeneous cohort and perhaps reducing power to identify such factors as predictors. A recent study showed that the association between black ethnicity and paediatric asthma re-admissions was strongly confounded by socioeconomic factors [37], possibly explaining why Afro-Ecuadorian ethnicity was not a predictor in our study. Further studies in similar LMICs are necessary to clarify the respective roles of socioeconomic status and ethnicity as determinants of asthma attack risk.

Asthma in the presence of atopy is associated with other allergic diseases including eczema and rhinoconjunctivitis. Children with concomitant allergic diseases may have a higher risk of future asthma attacks [38], as observed here for children with a previous eczema diagnosis. Eczema has been associated with poor asthma control among children in urban Brazil [38]. Individuals with allergic asthma appear to be particularly susceptible to virus-induced exacerbations [39], and suppression of allergic mediators reduces virally mediated attacks [40]. However, in our study we did not observe associations between allergy markers (blood and nasal eosinophilia, and $F_{\mathrm{eNO}}$ ) or allergic sensitisation (specific IgE) and risk of asthma attack recurrence. Further studies are necessary to better understand the nature of this association.

Similarly, there was a greater risk of repeated severe asthma attacks among children describing food as a trigger (food allergies, colourants or cold foods). A previous population-based study from the UK has shown an association between food-induced wheeze in children and more frequent attacks of wheeze and healthcare use [41]. However, the mechanisms involved in food-induced asthma are not well understood and are not solely immunological, making it difficult to diagnose [42]. This was observed in our cohort, where there was no association between reported food triggers and a positive IgE to food extracts. Similarly, most children reported cold drinks/foods (physical agents) as the triggers of their food-induced asthma.

Predictors of recurrent asthma attacks could be combined into a risk assessment tool to identify children with good symptom control but at high risk of attacks, a group representing half of those in our study. To be able to reduce the risk in these children, a complete asthma management package would need to be implemented: supply of free medication, individualised asthma action plan, training for inhaler technique, close monitoring of adherence and control of comorbidities and modifiable lifestyle and environmental risk factors.

TABLE 4 Multivariable Cox regression model for emergency room re-attendance for severe asthma attacks

Crude HR p-value Adjusted HR ${ }^{\#}$ p-value

(95\% Cl) $\quad(95 \% \mathrm{Cl})$

\begin{tabular}{|c|c|c|c|c|}
\hline Age & $0.92(0.87-0.97)$ & 0.002 & $0.93(0.88-0.98)$ & 0.009 \\
\hline Previous asthma diagnosis & $1.78(1.26-2.53)$ & 0.001 & $1.66(1.15-2.39)$ & 0.007 \\
\hline $\begin{array}{l}\text { Number of i.v./i.m. corticosteroid courses } \\
\text { during past } 12 \text { months }\end{array}$ & $1.17(1.10-1.24)$ & $<0.001$ & $1.13(1.06-1.20)$ & $<0.001$ \\
\hline Urban residence & $0.65(0.47-0.89)$ & 0.007 & $0.69(0.50-0.95)$ & 0.023 \\
\hline
\end{tabular}

HR: hazard ratio; i.v.: intravenous; i.m.: intramuscular. $\mathrm{n}=270 .{ }^{\#}$ : adjusted hazard ratios were adjusted for all other variables in the model. 


\section{Strengths and limitations}

Our study had a number of limitations. First, because all children were treated in accordance with local guidelines, the fact that this cohort of asthmatic children were followed-up, educated about their asthma and provided a written asthma action plan probably modified their outcomes through improved asthma knowledge, adherence to treatment and management of attacks. Second, although we initially aimed to start children on ICS following the Ecuadorian guidelines, the large number of children recruited and limited human resources available meant it was not possible to monitor the children and their adherence as closely as we would have liked. Third, the study population has certain characteristics (including ethnicity, socioeconomic status, asthma knowledge, low proportion of ICS use) that may differ from other Latin American settings and limit generalisability. Although attendance at ERs for treatment of attacks is part of the definition of a severe asthma attack according to the American Thoracic Society/European Respiratory Society statement [1], the severity of disease in our populations may be less than that observed in high-income settings where better management and alternative treatment options are available. However, the objective of the study was to identify predictors in a real-world setting to facilitate working towards a risk assessment tool that can be applied in ERs for any patient presenting with bronchodilator-responsive wheeze. Strengths of this study were adequate power to identify potential predictors and a high follow-up rate. The comprehensive questionnaire, inflammatory markers and lung function measurements were designed to explore a broad range of potential risk factors for asthma attack recurrence. By including all bronchodilator-responsive wheeze irrespective of previous asthma diagnosis or lung function parameters, this relatively nonselective sample represented more closely patients with real-life asthma attending ERs.

\section{Conclusion}

In conclusion, we performed a prospective study of children presenting with asthma attacks to ERs in a resource-poor setting in Ecuador and identified predictors of re-attendance with attacks and time to next attack. Approximately half of the recruited asthmatic children suffered a subsequent asthma attack within 6 months of follow-up. Several predictors were identified including a previous asthma diagnosis and an asthma attack during the previous year requiring systemic corticosteroids. A combination of these predictors could be used as a simple risk-assessment tool in ERs to identify asthmatic children at a higher risk of recurrent attacks. Such a tool would be extremely useful in LMICs where limited resources should be targeted towards those most in need of continuing support and treatment. Further studies are now required to validate our findings in different low-resource settings.

Conflict of interest: C. Ardura-Garcia has nothing to disclose. E. Arias has nothing to disclose. P. Hurtado has nothing to disclose. L.J. Bonnett has nothing to disclose. C. Sandoval has nothing to disclose. A. Maldonado has nothing to disclose. L.J. Workman has nothing to disclose. T.A.E. Platts-Mills has nothing to disclose. P.J. Cooper reports grants from PATH Vaccines and National Institutes of Health Research, outside the submitted work. J.D. Blakey reports personal fees and non-financial support from Astra Zeneca, Boehringer Ingelheim and Napp, personal fees from Teva and non-financial support from Novartis, outside the submitted work.

Support statement: This research was funded by a Wellcome Trust Clinical PhD Fellowship granted to C. Ardura-Garcia (grant 099938/B/12/Z). Funding information for this article has been deposited with the Crossref Funder Registry.

\section{References}

1 Reddel HK, Taylor DR, Bateman ED, et al. An official American Thoracic Society/European Respiratory Society statement: asthma control and exacerbations: standardizing endpoints for clinical asthma trials and clinical practice. Am J Respir Crit Care Med 2009; 180: 59-99.

2 O'Byrne PM, Pedersen S, Lamm CJ, et al. Severe exacerbations and decline in lung function in asthma. Am J Respir Crit Care Med 2009; 179: 19-24.

3 Hasler G, Gergen PJ, Kleinbaum DG, et al. Asthma and panic in young adults: a 20-year prospective community study. Am J Respir Crit Care Med 2005; 171: 1224-1230.

4 Neffen H, Gonzalez SN, Fritscher CC, et al. The burden of unscheduled health care for asthma in Latin America. J Investig Allergol Clin Immunol 2010; 20: 596-601.

5 Covar RA, Szefler SJ, Zeiger RS, et al. Factors associated with asthma exacerbations during a long-term clinical trial of controller medications in children. J Allergy Clin Immunol 2008; 122: 741-747.

6 Ernst P, Baltzan M, Deschênes J, et al. Low-dose inhaled and nasal corticosteroid use and the risk of cataracts. Eur Respir J 2006; 27: 1168-1174.

7 Loke YK, Blanco P, Thavarajah M, et al. Impact of inhaled corticosteroids on growth in children with asthma: systematic review and meta-analysis. PLoS One 2015; 10: e0133428.

8 Suissa S, Baltzan M, Kremer R, et al. Inhaled and nasal corticosteroid use and the risk of fracture. Am J Respir Crit Care Med 2004; 169: 83-88.

9 Bousquet J, Mantzouranis E, Cruz AA, et al. Uniform definition of asthma severity, control, and exacerbations: document presented for the World Health Organization Consultation on Severe Asthma. J Allergy Clin Immunol 2010; 126: 926-938.

10 Cameron A, Ewen M, Ross-Degnan D, et al. Medicine prices, availability, and affordability in 36 developing and middle-income countries: a secondary analysis. Lancet 2009; 373: 240-249. 
11 Ardura-Garcia C, Vaca M, Oviedo G, et al. Risk factors for acute asthma in tropical America: a case-control study in the City of Esmeraldas, Ecuador. Pediatr Allergy Immunol 2015; 26: 423-430.

12 Neffen H, Fritscher C, Schacht FC, et al. Asthma control in Latin America: the Asthma Insights and Reality in Latin America (AIRLA) survey. Rev Panam Salud Publica 2005; 17: 191-197.

13 Li P, To T, Guttmann A. Follow-up care after an emergency department visit for asthma and subsequent healthcare utilization in a universal-access healthcare system. J Pediatr 2012; 161: 208-213.

14 Smiley M, Sicignano N, Rush T, et al. Outcomes of follow-up care after an emergency department visit among pediatric asthmatics in the military health system. J Asthma 2016; 53: 816-824.

15 Zipkin R, Schrager SM, Nguyen E, et al. Association between pediatric home management plan of care compliance and asthma readmission. J Asthma 2017; 54: 761-767.

16 Ardura-Garcia C, Stolbrink M, Zaidi S, et al. Predictors of repeated acute hospital attendance for asthma in children: a systematic review and meta-analysis. Pediatr Pulmonol 2018; 53: 1179-1192.

17 International Study of Asthma and Allergies in Childhood (ISAAC) Phase Two Study Group. ISAAC Phase Two Study Modules. 1998. http://isaac.auckland.ac.nz/phases/phasetwo/phasetwomodules.pdf Date last accessed: February 2013.

18 Cooper PJ, Chico ME, Bland M, et al. Allergic symptoms, atopy, and geohelminth infections in a rural area of Ecuador. Am J Respir Crit Care Med 2003; 168: 313-317.

19 Cooper PJ, Chico ME, Vaca MG, et al. Effect of albendazole treatments on the prevalence of atopy in children living in communities endemic for geohelminth parasites: a cluster-randomised trial. Lancet 2006; 367: 1598-1603.

20 Liu AH, Zeiger R, Sorkness C, et al. Development and cross-sectional validation of the Childhood Asthma Control Test. J Allergy Clin Immunol 2007; 119: 817-825.

21 Nathan RA, Sorkness CA, Kosinski M, et al. Development of the asthma control test: a survey for assessing asthma control. J Allergy Clin Immunol 2004; 113: 59-65.

22 Ingram JM, Rakes GP, Hoover GE, et al. Eosinophil cationic protein in serum and nasal washes from wheezing infants and children. J Pediatr 1995; 127: 558-564.

23 Juniper EF, Guyatt GH, Feeny DH, et al. Measuring quality of life in children with asthma. Qual Life Res 1996; 5: 35-46.

24 Fitzclarence CA, Henry RL. Validation of an asthma knowledge questionnaire. J Paediatr Child Health 1990; 26 : 200-204.

25 Praena Crespo M, Lora Espinosa A, Aquino Llinares N, et al. Versión española del NAKQ. Adaptación transcultural y análisis de fiabilidad y validez [The Spanish version of the Newcastle Asthma Knowledge Questionnaire for parents of children with asthma (NAKQ). Transcultural adaptation and reliability analysis]. An Pediatr 2009; 70: 209-217.

26 Ecuadorian Society of Pneumology, Ecuadorian Society of Allergy and Immunology, Ecuadorian Academy of Otorhinolaryngology, Ecuadorian Thorax Society. Ecuadorian Asthma and Allergic Rhinitis Consensus. Quito, PLM Ecuador, 2011

27 Bateman ED, Hurd SS, Barnes PJ, et al. Global strategy for asthma management and prevention: GINA executive summary. Eur Respir J 2008; 31: 143-178.

28 SEPAR, SEAIC, SEORL, semFYC, SEMERGEN, SEMG, GRAP, SEICAP and SENP. GEMA 2009. Guía Española para el Manejo del Asma [Spanish guide for asthma management]. Madrid, Luzán 5 S.A. de Ediciones, 2009.

29 Collett D. Modelling Survival Data in Medical Research. 3rd Edn. New York, Chapman and Hall/CRC, 2014

30 Hosmer D, Lemeshow S, Sturdivant R. Assessing the fit of the model. In: Hosmer DW, Lemeshow S, Sturdivant RX, eds. Applied Logistic Regression. 3rd Edn. New York, John Wiley \& Sons, 2013; pp. 163-223.

31 Harrell FE, Califf RM, Pryor DB, et al. Evaluating the yield of medical tests. JAMA 1982; 247: 2543-2546.

32 Harrell FE, Lee KL, Mark DB. Multivariable prognostic models: issues in developing models, evaluating assumptions and adequacy, and measuring and reducing errors. Stat Med 1996; 15: 361-387.

33 Amorim MM, Araruna A, Caetano LB, et al. Nasal eosinophilia: an indicator of eosinophilic inflammation in asthma. Clin Exp Allergy 2010; 40: 867-874.

34 Wesseldine LJ, McCarthy P, Silverman M. Structured discharge procedure for children admitted to hospital with acute asthma: a randomised controlled trial of nursing practice. Arch Dis Child 1999; 80: 110-114.

35 Canino G, Garro A, Alvarez MM, et al. Factors associated with disparities in emergency department use among Latino children with asthma. Ann Allergy Asthma Immunol 2012; 108: 266-270.

36 Busse WW, Lemanske RF Jr, Gern JE. Role of viral respiratory infections in asthma and asthma exacerbations. Lancet 2010; 376: 826-834.

37 Beck AF, Huang B, Simmons JM, et al. Role of financial and social hardships in asthma racial disparities. Pediatrics 2014; 133: 431-439.

38 de Magalhães Simões S, da Cunha SS, Cruz AA, et al. A community study of factors related to poorly controlled asthma among Brazilian urban children. PLoS One 2012; 7: e37050.

39 Soto-Quiros M, Avila L, Platts-Mills TA, et al. High titers of IgE antibody to dust mite allergen and risk for wheezing among asthmatic children infected with rhinovirus. J Allergy Clin Immunol 2012; 129: 1499-1505.

40 Teach SJ, Gill MA, Togias A, et al. Preseasonal treatment with either omalizumab or an inhaled corticosteroid boost to prevent fall asthma exacerbations. J Allergy Clin Immunol 2015; 136: 1476-1485.

41 Kuehni CE, Strippoli MF, Silverman M. Food intolerance and wheezing in young South Asian and white children: prevalence and clinical significance. J Allergy Clin Immunol 2006; 118: 528-530.

42 Wilson NM. Food related asthma: a difference between two ethnic groups. Arch Dis Child 1985; 60: 861-865. 